\title{
ÉTICA E PRÁTICA POLÍTICA EM GANDHI
}

\author{
ADAMS, Jad. \\ Gandhi: ambição nua. \\ São Paulo: Geração Editorial, 2012. 464 p. \\ POR
}

Dagmar Manieri ${ }^{1}$

\begin{abstract}
Todo aquele que tem um razoável conhecimento das Ciências Humanas não desconhece a figura de Nicolau Maquiavel, o pensador florentino de início do 1 século XVI que propugnou a ausência da ética na prática política. Segundo Maquiavel, a ética representa um obstáculo no intento do líder político (o "príncipe") de erigir uma nova ordem sócio-política.
\end{abstract}

Por isso quando nos aproximamos de um personagem histórico como Gandhi, logo nos perguntamos: ele reverte a afirmação de Maquiavel? Na biografia de Jad Adams, Gandhi: ambição nua, esse questionamento não é essencial. Adams procura, como 0 próprio titula da obra sugere, desmistificar a figura de Gandhi. 0 "ataque" de Adams ocorre de vários lados: sexual, político, relacionamento familiar, etc.

Sobre o tema da sexualidade, Adams concede um espaço exagerado. Sua interpretação expressa que embora Gandhi recomendasse o celibato, ele dormia com algumas jovens de seu ashram (comunidade religiosa). Primeiro com Sushila, depois com Manu e, finalmente, com Abha. No final, ele dormia com as duas últimas ao mesmo tempo. Adams vai até ao diário de Manu e resgata essa fala de Gandhi: “(...) devemos começar a dormir juntos e nus" (p.391). E completa: "Devido à atração da fama, todos os relatos sugerem que não faltavam jovens mulheres dispostas a servir Gandhi da forma que ele desejasse (p.396). Essa experiência de dormir com as jovens, segundo o autor, era um teste para verificar sua firmeza em lidar com seu próprio corpo.

\footnotetext{
${ }^{1}$ Professor Adjunto do Curso de História, Colegiado de História (Araguaína) da Universidade Federal do Tocantins, Brasil.dagmarmanieri@bol.com.br
} 
Com relação à abordagem política de Gandhi, Adams apreende bem a noção de satyagraha, que implica em desobediência civil sem o uso da violência. Gandhi, portanto, inverte Maquiavel. 0 que para este último é sentido como fraqueza (a ética), em Gandhi se transforma em força política. Gandhi por várias vezes afirmou que 0 satyagraha nada tem de passivo, na medida em que mobiliza politicamente um conjunto de indivíduos submissos e explorados. A desobediência implica em uma atitude ativa, como por exemplo, entrar (sem o visto) em uma região (o Transvaal) legalmente interditada aos indianos. Ao sofrer as primeiras reações do poder dominante, o satyagrabi (o militante) procura forçar sua detenção. É assim, também, que Gandhi realiza sua prática política: ele induz uma reação ao poder para que este se mostre uma potência desmedida, injusta, deixando visível a injustiça de uma lei. Então, com 0 satyagraba, forma-se uma dualidade. De um lado, a "verdade", a "ética", a "bondade"; de outro, a "injustiça". Desse modo, o satyagraha (como prática política) é uma forma de alterar o atual estado de coisas, através do uso da ética. Satyagraha é uma forma de retirar a força (política) que há no elemento ético.

Todavia, isso não se realiza de uma forma mecânica. Gandhi treinava seus satyagrahis para que eles executassem determinadas ações. Na medida em que 0 movimento de mobilização política se estendia para outros grupos, o movimento tendia a tomar a forma de violência. Eis o grande desafio para Gandhi. Eram nessas ocasiões que, provavelmente, ele se sentia culpado, pois ocorriam diversas mortes e, como forma de reação (e protesto), ele jejuava ao tomar ciência de que algum membro de seu ashram infringira uma norma. Adams comenta que foi na África do Sul que Gandhi aperfeiçoou essa prática. Aliás, o jejum será uma grande arma política: quando 0 Mahatma (grande alma) jejuava e ficava perto da morte era um fator de preocupação geral, o que obrigava as partes a procurarem um acordo, ainda que transitório. 0 jejum era, assim, uma tática especial de Gandhi que visava conquistar por sua docilidade e simpatia e chocar seu oponente através do auto-sofrimento.

0 grande erro de Jad Adams em sua biografia de Gandhi é não compreender a especificidade da prática política ghandhiana. Ele acentua que "Gandhi foi um grande líder, mas um deplorável político (...)”, afirmando que o mesmo não sabia negociar, pois não procurava um entendimento possível para determinada circunstância política. Para ele, Gandhi aplicava seu tradicionalismo religioso (que vê só as "verdades absolutas") na ordem política, porém, quando Adams vê um Gandhi lutando por causas que estão longe de seus ensinamentos políticos, sua única saída é ver uma contradição.

Adams se apega à tese da "ambição" de Gandhi: "A ambição não era conseguir justiça para os trabalhadores ou a independência da Índia - essas eram exigências transitórias. 0 objetivo de Gandhi nada mais era do que a perfeição espiritual”. Como podemos ver, Adams não resolve o problema da "contradição", muito menos lhe dá uma 
saída satisfatória. Crer que a "perfeição espiritual" é uma ambição, isto sim é que é uma contradição.

Gandhi tinha uma meta para si e para aqueles que estavam ao seu lado no ashram. Para aqueles mais distantes executava uma prática social. Gandhi não renunciou ao mundo, como muitos gurus indianos. 0 próprio Adams descreve sua luta contra o sistema de exclusão dos intocáveis (a casta desprezível, no hinduísmo). Gandhi também militava no sentido de alterar o comportamento dos indianos, infundindo-lhes noções básicas de higiene. Como bom tradicionalista, foi cada vez mais se conscientizando da necessidade de boicotar os produtos ingleses, principalmente seus tecidos. Os membros do ashram tinham que saber realizar trabalhos manuais, principalmente a tradicional forma de fiar com as rocas. Por isso Adams comenta que 0 grande ideal nacional de Gandhi, além da emancipação da Índia, era um país com uma vida tradicional, com suas aldeias autosuficientes. Daí não ser correto, como faz Adams, confundir a prática sócio-política de Gandhi com seu objetivo de aperfeiçoamento espiritual. Entre a realidade sócio-política e a meta de autocontrole havia uma enorme distância: era essa a visão de Gandhi.

0 que é inédito na prática política de Gandhi é sua rejeição a Maquiavel. Pela primeira vez na história contemporânea, um grande líder político empreende uma prática política longe do modelo maquiavélico. 0 satyagraha não representa uma simples prática política: exige treinamento de seu adepto. A técnica exige um autocontrole, um domínio de si contra 0 instinto de violência. Assim, politização implica em domínio de si, somado a uma atitude ativa diante da vida social.

Dois acontecimentos concretos podem ser indicados a título de exemplo sobre os limites do gandhismo. 0 primeiro deles é a invasão nazista, sobre a qual Jad Adams cita algumas passagens de Gandhi nas que "elogia" Hitler: "Eu não desejo que os aliados sejam derrotados, mas não considero que Hitler seja tão ruim quanto dizem". A questão não é essa falsa apreciação de Hitler, mas, como reage o gandhismo ante uma política agressiva ao estilo nazista? Adams comenta que em 1940, Gandhi escreve uma carta a Hitler, dirigindo-se ao líder como "caro amigo": "Não temos dúvida quanto à sua bravura ou devoção à sua pátria, como também não acreditamos que você seja 0 monstro descrito por seus oponentes, embora muitos de seus atos tenham sido monstruosos e impróprios da dignidade humana, especialmente no estigma de homens como eu, que acreditam na amizade universal" (p.339). Gandhi aqui levava ao extremo uma das características do satyagraha: de crer em numa certa bondade no adversário. Na resposta ao nacionalismo indiano, Adams afirma que Hitler havia dito: "0 que você deve fazer é matar Gandhi e, se necessário, outros líderes do Congresso". A crítica do autor finaliza afirmando que Gandhi, pelo menos, teve "a coragem moral de admitir a sua impotência", mas localiza um dos limites do gandhismo: “(...) uma falha subjacente e persistente na compreensão do mal radical", que ocorre porque por não ser 
uma prática essencialmente social, com um viés político; daí por que se for empregado na ordem superior dos Estados, em que presenciamos um equilíbrio instável e sujeito a perturbações, ele pode levar a ordem política a uma submissão, por acreditar na reversão do quadro em longo prazo. 0 gandhismo é uma tática de resistência política e de reconstrução social e não de prevenção ou ataque defensivo.

0 segundo caso-limite pode ser encontrado nos tumultos em Calcutá. Em 19470 conflito hindu/muçulmano explode em várias regiões da Índia, no qual morrem milhares de pessoas em Punjab e na região de Calcutá. Gandhi, como sempre, dirige-se para essas regiões em busca da pacificação, sofrendo um atentado de assassinato. No auge dos conflitos, Gandhi comenta se sentir perdido. Adams acentua que alguns líderes do Congresso não desejavam aplicar o gandhismo (a não violência), já que era preciso intervir urgentemente, ao qual Gandhi responde utilizando sua única arma: o jejum. Segundo Adams: "Assim que o jejum foi anunciado na noite de $1^{\circ}$ de setembro [1947], ele já causava o seu efeito: os crimes e os saques diminuíram" (p.406). Gandhi utilizava-se de sua fama mundial, bem como de seu carisma junto ao povo, para debelar esses intensos conflitos religiosos. Mas, sua prática política do jejum era tão singular, que no meio político internacional era vista como uma tática astuta. Churchill, certa vez, referiu-se a Gandhi como "o velho malandro"; o governador das Províncias Unidas, Maurice Hallett, considerou-o "tão esperto quanto uma carreta lotada de macacos". Certo é que em muitos círculos, desconfiava-se desses jejuns de Gandhi, chegando-se a ventilar que suas secretárias aplicavam glicose em sua água, porém, Adams confidencia que nada disso foi comprovado.

E, se mesmo através do jejum o tumulto prosseguir? Neste último caso-limite do gandhismo, o líder entrega os fatos "na mão de Deus", o que ocorreu, em parte, nos anos que precederam à Independência da Índia. Gandhi chegou a afirmar que a Índia, após o domínio britânico, pudesse passar por um período de caos, uma época de "banho de sangue". Seu próprio plano de manter uma Índia unida sob o comando hindu era, visivelmente, ameaçador. Por isso seus esforços em conter 0 ímpeto mulçumano.

A política para Gandhi é uma prática social, que implica em aceitar a diferença (religiosa), convivendo com ela sem discriminação. Também é uma forma de aperfeiçoamento individual, na medida em que cada um se responsabiliza pelo bemestar da comunidade. 0 gandhismo almeja um indivíduo modesto, religioso, asseado, trabalhador e cioso da tradição. É radical porque não lutara só contra o domínio britânico, mas também contra a civilização ocidental moderna. A ação de Gandhi foi benéfica para a configuração da Índia pós-Independência, pois sem ele a Índia poderia ter se transformado em um caos, o que implica na multiplicação das vítimas na guerra religiosa. 
Não obstante, no severo julgamento de Jad Adams em relação ao líder indiano, esse aspecto não é reconhecido. No balanço final da obra que Adams intitula "Legado", há um saldo negativo do gandhismo. Adams não percebe (ou se "percebe", julga mal) que Gandhi utiliza a ética como arma política e que o gandhismo é, essencialmente, uma prática sócio-política de reação:

(...) sua visão moral era profunda, mas dizia respeito à realização individual. Ele podia conceber a animosidade pessoal, mas a destruição genocida estava além de sua compreensão. Quando confrontado com a maldade em massa - os massacres armênios, os massacres japoneses, o Holocausto Nazista -, a sua filosofia vacilava (p.424).

Para fundamentar sua tese de que Gandhi priorizava o lado subjetivo do homem, desmerecendo o objetivo (a política e o social, em si), Adams cita algumas passagens do líder, nas que este afirma que as "atividades externas" e as "[suas] políticas" são a parte "mínima" de seu ser. Mas, isso não desmerece a importância da militância de Gandhi nas áreas social e política. 0 que resta de positivo, na visão de Adams, é um Gandhi "heróico, o guerreiro metafísico".

0 gandhismo deve ser entendido no contexto dos modelos de prática política existentes desde a era moderna. Se Simon Bolívar tentou, sem resultado, esquivar-se de uma prática maquiavélica; por outro lado, Gandhi conseguiu seu intento. Sua prática política implica no retorno da ética à ordem política. Mesmo consciente dos limites do gandhismo, este provou que novas formas de prática política podem ser experimentadas longe do tradicional modelo maquiavélico. A perpetuação deste último, abalado momentaneamente com a experiência totalitária, comprova que tal modelo é apenas uma parte, uma dimensão, do vasto campo das estratégias políticas. Gandhi por isso mostrou que outra forma de política pode existir, agora com o exercício da ética e sem 0 temor de se mostrar como "verdade". 